\title{
Research of Practical Teaching System of Software Quality Assurance and Testing Based on Large-scale Engineering Practice
}

\author{
Luo Siqing ${ }^{1, a}$, Li Li ${ }^{1, b}$, Bian Jilong ${ }^{1, c, *}$, Zhang Xiying ${ }^{1, d}$, Li Yan ${ }^{1, e}$ \\ ${ }^{1}$ College of Information and Computer Engineering in Northeast Forestry University, Harbin, \\ Heilongjiang, 150040 \\ a1035736474@qq.com, b63451751@qq.com, c67313127@qq.com, d29791013 @qq.com, \\ e2268700179@qq.com
}

${ }^{*}$ Corresponding author

Keywords: large-scale engineering model; software engineering; practical teaching system; practical teaching standards.

\begin{abstract}
This paper, taking software engineering in Northeast Forestry University as an example, summarizes the experience of its practical teaching reform and development from the training objectives and curriculum system after studying the large-scale and complex engineering model. It aims at building an effective teaching system, so as to arouse students' learning enthusiasm and constantly improve the practical teaching standards.
\end{abstract}

\section{Introduction}

Software Quality Assurance and Testing is a compulsory core course of software engineering major. It aims at studying how to improve quality of software product, develop students' theoretical knowledge and practical ability of software quality assurance and software testing during software development and management. The course systematically analyzes the causes of software defects in the process of software development and management and elaborates on the strategies, methods and techniques for discovering various defects. The module includes the basic concepts of software engineering, software quality, ideas and methods of software quality assurance, basic theories and techniques of software testing, testing strategies, testing models and procedures, and skills improving software testing, as well as test management and writing documents ${ }^{[1]}{ }^{[2]}$. Through the learning of this course, students can master the ideas and methods of software quality assurance systematically, comprehensively use software testing principles, methods and techniques to test software projects, and master the engineering methods of software testing, to make the testing process more standardized and improve the quality of software, thereby developing students' overall quality ${ }^{[3]}$.

\section{Necessity of the Practical Teaching Research}

\subsection{To Meet the Demands of Social Development}

With the ever-increasing scale and complexity of software systems, the variety of losses resulting from software defects are also greatly raising, which can bring catastrophic consequences. Software quality testing as an effective means of software quality assurance is attracting more and more attention, so that the importance of the research and application of software testing methods and techniques becomes more significant. Therefore, it is an essential part of teaching reform in software engineering, as well as an inevitable result of social development, to establish an effective and sustainable practical teaching system in line with the discipline of the major, and thus train students' engineering ability and innovation ability to achieve the standards of excellent engineers and the ultimate goal of software engineering training. 


\subsection{To Meet the Demands of Software Engineering}

From the view of students' abilities, students trained in software engineering major must have the ability of project management, software analysis and design, software maintenance, software quality management and software testing. In addition, they should be equipped with solid software engineering knowledge and skills, good foreign language application, strong teamwork spirit and technical innovation, excellent professional accomplishment and international competition consciousness. The acquisition of these applied abilities relies to a large extent on the experimental teaching system based on theoretical knowledge. Thus, it is necessary to develop its professional features, such as strong application, construct a complete practical teaching system and its safeguard measures, and strengthen students' practical ability. In this way, students not only can ask questions and analyze problems, but also can solve problems, with strong applied ability and vocational ability to become talents needed by the society.

From the characteristics of software quality assurance and testing, it is a course that combines both theory and practice, which has important theoretical value and strong practicality. Its purpose is to train students to master the software quality management methods and software testing, as well as the present popular software testing tools. In actual teaching, students are required not only to master the basic theoretical knowledge, but also to develop practical ability to analyze and solve problems in practice. This course enables students to master the basic design principles and methods of software engineering, and design suitable solution for software testing problems. Students can understand and master the test methods from the scientific methodology, and use software testing tools for experiment, simulation and test.

\subsection{To Guarantee Talents Training}

Since society needs software talents with high practical ability, practical teaching is important to cultivate students' ability to understand and observe society, their application ability and operation skills. Meanwhile, it is also an effective way to consolidate theoretical knowledge, an important part of cultivating applied talents with high-quality and innovative ideas, and an essential platform for linking theory with practice and developing students' ability to master scientific methods and improve their practical ability. In order to meet the needs of the society and the goal of cultivating professionals, it is necessary to establish a scientific and effective practical teaching system, which enables students to integrate the courses they have learned. The simple compilation of course knowledge should be avoided, and the learned knowledge should be applied in practice, so that students can master the basic design principles and methods of software engineering and design a reasonable solution of complex engineering problems.

\subsection{Problems about the Practical Teaching}

Practice teaching of software quality assurance and testing aims at understanding and mastering the basic ideas, basic concepts, analysis methods, basic theories, testing strategies, testing models and testing procedures of software testing. It can improve the software testing skills, test management capabilities and document writing ability, enable students to comprehensively use software testing principles, methods and techniques to carry out software project testing with the commonly used testing tools, improve software quality management and lay foundation for the future students in software development and testing. However, some problems have been existing in the actual teaching process, which is not beneficial for training software testing talents.

Firstly, the software quality assurance and testing is not valued highly. A survey found that though some colleges and universities have fully understood the position of software testing which is thought a good job, software testing is regarded only as a supplementary work, which is cumbersome and fragmentary without technical content. They ignore the importance of software testing in the software development ${ }^{[4]}$, which has led to a lack of emphasis on software quality and testing course.

Secondly, the training system of practical ability is incomplete. According to the survey of graduates' working conditions and software testing employers, it is found that enterprises require 
students not only to have good professional knowledge and master the software system development and design, but also to have practical skills and certain development experience. However, the practical teaching of software quality and testing course is generally ignored, such as the weak, poor and close practice, and lack of necessary practical training, as well as comprehensive and unique teaching plan. In addition, comprehensive and innovative practical content with a certain depth and breadth is more difficult to be complemented, so that the lack of a sound practice teaching system makes students' application capacity not be developed.

Thirdly, the practical environment of software testing is single. The purpose of software testing identify various potential software errors and defects with best efficiency, to avoid the resulting risks and improve the quality of the software by correcting errors and defects. And students have the ability to choose the right test method and technology to design the test program for practical problems, and analyze the test results to provide the basis for the corresponding treatment. Thus, in the course of software quality assurance and testing, we should focus on training students to master the technology and basic skills of software testing, and be proficient in using software testing tools to comprehensively apply their knowledge, analyze and solve problems. At present, in some schools the practice and training are simulated in the laboratory, without a real background of system development, which will result in that students do not pay attention the course and cannot integrate software engineering ideas into the system development. Finally, students are not good at finding problems and solving problems, system analysis and design, management and collaboration and other aspects, which are the necessity for talents of the information management and information system. At the same time, schools generally have no regular communication with each other in practice, resulting in the artificial separation of the existing regular links between the various practical aspects. The process of practice appears to be repeated, mutually different and separated, and even faces lack of some knowledge points, which is not conducive to students' ability to apply and innovate.

\section{Establishment of Practice Teaching System}

\subsection{Teaching Objectives and Thoughts}

Practical teaching is a key link in the teaching system and plays an irreplaceable role in the training of creative talents. The practical teaching mode is conductive to teach students scientific knowledge, thinking methods and operation skills in a planned and organized way, which can guide students to create and design so as to improve their qualities, develop their potentials and personality, expand their thinking and inspire them to study practical issues. Then, they would have three kinds of ability. The first is practical technical ability to understand and master software development technology. The second is the ability to analyze and solve problems independently. The third is project quality to follow the software engineering process and norms through engineering training.

In the process of practical teaching, a "hierarchical, modular and gradual" model is formulated. The content of the teaching is from low to high and from single to comprehensive, in terms of "understanding of software quality assurance and testing", "basic training" and "comprehensive training". It can combine theory with practice in different stages and follow the law of "practice cognition - improvement - re-practice - re-understanding - re-improvement".

\subsection{Teaching Content}

\subsubsection{Basic Knowledge}

In the process of cultivating students, the practical process and the life cycle of software engineering are organically integrated and organized according to the conception, design, implementation and operation. Practice is divided into basic practice, comprehensive design practice, and open practice. In the practical contents embody the ideas of project design. Take a completed project as a case through which all levels of practice is integrated so than contents are made into an organic whole to connect software testing with software development techniques. This process focuses on expressing engineering problems of software quality assurance and testing with 
mathematical and natural science knowledge and the basic knowledge of the course, to establish models and correctly solve, abstract, induce and control of engineering problems .

\subsubsection{Training Platform of Software Testing}

With tools such as Loadrunner and IBMRationl, students should be able to select and apply software engineering methods and test tools, analyze and compare, predict and simulate the design of complex engineering problems encountered during software quality testing. And they should understand and express the limitations of the solution, so as to improve and train students' techniques and capabilities in large-scale software testing from an engineering point of view.

\subsection{Practical Teaching Mode}

(1) Project Teaching. Through the teaching and practice training of typical cases, students can understand and master improvement and management of software quality assurance, and the status and function of software testing in software life cycle and software engineering, as well as features, methods and models of object-oriented software testing. In addition, they can grasp the basic skills of developing testable models and conducting software test design, and achieve the goal of test design, implementation and management according to software requirements, with certain modern scientific and technological methodology.

Teachers assign the problem or tasks to be completed in the form of projects to the students. Under the guidance of the teacher, students make plans together and complete the projects as a whole or group, in accordance with the whole actual work of a complete process. During the period, students understand and grasp the knowledge and skills required by curriculum, and develop ability to analyze and solve problems, team spirit and cooperation. The project teaching can be guided by teachers of the actual scientific research project, or other personnel in software company with strong professional background through school-enterprise cooperation. For example, software company Neusoft can provide the appropriate training, as students enjoy its business background.

(2) Case Teaching. In the process of case analysis, we should combine the theoretical knowledge effectively, introduce the students into a specific simulation site, deepen the role of the case scenario, and train students to improve their practical ability to manage knowledge through discussion and analysis. It should focus on timely analysis, and evaluation which should positively encourage students' thinking. Teachers should praise students with fresh ideas and insightful opinion, and euphemistically induce students with wrong thinking. Students are inspired to think from various aspects, to avoid cracking down on their enthusiasm for learning.

(3) Simulated teaching. Simulated experimental teaching is conducive to the training of management personnel in the information age, which will help enhance students' innovative awareness and help students digest and integrate theoretical knowledge ${ }^{[6]}$. The main teaching contents are as follows. The first is simulation of management information system, mainly to cultivate students understand and master the methods and techniques of system development, write the corresponding computer simulation program according to the software engineering methods, and analyze the results of the system operation. In the process of system development and simulation, to study and understand the mature software, experts should be invited to do special reports in the system development, which can guide students' development. The second is ERP simulation practice that can simulate the real business production and management through building a simulated enterprise environment. It aims at helping students apply the learned to independently analyze and solve the actual problem through combination of the real sand table and ERP management software.

(4) practical teaching through school-enterprise cooperation. Practical teaching is an important part of teaching in colleges and universities to cultivate students practical ability and ability to innovate. In order to keep abreast of the social needs of software testers, schools should train students' social job quality and employment competitiveness, and thus the enterprise resources should be introduced into practical teaching process. According to actual needs, the decentralized and centralized management mode can be taken. Business and technical personnel can be employed as part-time teachers to undertake practical teaching tasks. Teachers can also lead students to enter 
the enterprise or to observe or participate in the testing of software projects. The technical personnel of the enterprise can explain the techniques and methods of software quality assurance and testing so that the learning is more targeted and realistic to improved students application.

\section{Summary}

In summary, since the design and organization of the practical teaching process of software quality assurance and testing course is complex and scientific, it should meet the training objectives of software engineering. And the construction of the experimental teaching system should be based on meeting the needs of the society for software testing talents. It is significant to cultivate the application ability of software engineering from the needs of society and the scientific development, and train software testing talents with good theoretical knowledge, applied skills and high quality for the development of social information, in order to promote the disciplinary construction of software engineering and its continuous development.

\section{Acknowledgement}

This is a project funded by key curriculum project of Northeast Forestry University (2015) and New century teaching reform project of higher education in Heilongjiang Province (2016).

\section{References:}

[1] Yu Haiying. A Study on Teaching Reform of Software Quality Assurance and Testing [J]. CC News, 2016 (2): 155-156.

[2] Yang Li. Research of Teaching Reform and Practice of Software Testing Technology [J]. Education Teaching Reform, 2014 (41): 2007, 20 (3): 63-65.

[3] Deng linjuan. Exploration and Practice of Project Teaching Reform in Software Testing Technology Courses [J]. Journal of Qingyuan Polytechnic, 2016, 9 (1): 70-73 .

[4] Zhang Shiliang. Exploration on Teaching Reform of Software Testing Course in Colleges and Universities. Journal of Ningde Normal University (Natural Science), 2013, 25 (4): 415-417.

[5] Liu Xiaojun, Cao Yongchun. Analysis on the Teaching Reform of Software Testing Course [J]. Computer and Information Technology, 2014 (2): 124-126.

[6] Tong Yujun. Research and Exploration on Practical Teaching Reform of Software Engineering [J]. Journal of Liaoning University of Technology (Social Science), 2015, 17 (1): 113-115. 